\title{
Light microclimate of endolithic phototrophs in the scleractinian corals Montipora monasteriata and Porites cylindrica
}

\author{
Sveinn Haukur Magnusson ${ }^{1}$, Maoz Fine ${ }^{2}$, Michael Kühl ${ }^{1, *}$ \\ ${ }^{1}$ Marine Biological Laboratory, Department of Biology, University of Copenhagen, Strandpromenaden 5, 3000 Helsingør, Denmark \\ ${ }^{2}$ Centre for Marine Studies, University of Queensland, St. Lucia, Queensland 4072, Australia
}

\begin{abstract}
The light microclimate of phototrophic endoliths growing within the scleractinian corals Porites cylindrica and Montipora monasteriata was described by scalar irradiance microprobe measurements within different layers of the coral skeleton. Characterisation of the pigments in individual layers was done by reflectance spectroscopy with fibre-optic radiance microprobes. The spectral measurements showed the presence of an endolithic community largely comprised of the green alga Ostreobium sp. within a 1 to $2 \mathrm{~mm}$ thick green band 2 to $6 \mathrm{~mm}$ below the coral surface. Additionally, spectral signatures of cyanobacteria and anoxygenic phototrophic bacteria were detected both in the coral tissue-containing top layer and within the skeleton matrix. The light microclimate within the coral skeleton was extremely poor in visible light but enriched in far-red wavelengths. Only a fraction of the incident photosynthetically available radiation (PAR, 400 to $700 \mathrm{~nm}$ ) penetrated the coral tissue-containing layer, wherein 90 to $99 \%$ of the incident irradiance was attenuated due to intense scattering and absorption. Near-infrared radiation (NIR, >700 to $1000 \mathrm{~nm}$ ) was mainly scattered in the tissue-skeleton matrix and penetrated much deeper into the skeleton. Multiple scattering and light-trapping effects caused high NIR scalar irradiance levels in the topmost layers of the coral. Our data show that the endolithic community in healthy corals is strongly light-limited with respect to PAR, but not with respect to NIR in shallow waters where water absorption of NIR is not limiting. Light limitation of PAR is mainly imposed by the tissue-containing part of the coral, and could thus be alleviated during coral bleaching, resulting in blooming of the phototrophic endoliths.
\end{abstract}

KEY WORDS: Endolithic microalgae $\cdot$ Ostreobium $\cdot$ Scalar irradiance $\cdot$ Microenvironment $\cdot$ Optics Resale or republication not permitted without written consent of the publisher

\section{INTRODUCTION}

Many scleractinian corals are inhabited by endolithic filamentous green algae of the genus Ostreobium (Siphonales: Chlorophyta) (Jeffrey 1968, Lukas 1973, 1974) and by endolithic cyanobacteria (Le CampionAlsumard et al. 1995, Ralph et al. in press). The endoliths reside within the calcareous skeleton, where they often form a dense green band underneath the coral tissue (Kanwisher \& Wainwright 1967, Highsmith 1981). Endolithic algae can provide energy to the coral, by transferring photoassimilates to the overlying coral tissue (Schlichter et al. 1996, Fine \& Loya 2002), and may also contribute reduced nitrogen (Ferrer \& Szmant 1989). The contribution of endolithic photosynthates to the coral energy budget is regarded as minor in comparison to the symbiotic zooxanthellae in coral tissues, because of the low metabolic rates of endoliths realised under the extremely dim light conditions within the skeleton (Kanwisher \& Wainwright 1967, Shashar \& Stambler 1992). However, endolith photosynthesis and biomass can be stimulated significantly under increasing irradiance (Fine et al. 2004) and this may lead to increased carbon translocation from the endoliths to the coral tissue. It has been speculated that such a stimulation of endolithic photosynthesis can be 
of great importance for the short-term survival and recovery of coral colonies in connection with loss of zooxanthellae during bleaching events (Fine \& Loya 2002, Fine et al. 2004).

Endolithic phototrophs are also an important energy source for sea urchins, parrotfish and other species grazing on corals (Schlichter et al. 1996), and endoliths play an important role in the bioerosion of coral reefs (Chazottes et al. 1995) both directly, through their ability to dissolve the skeleton matrix, and indirectly, through destruction of corals by corallivorous fishes (Bellwood 1995). Endolithic phototrophs are not limited to living corals, and are primary inhabitants of dead corals and other dead carbonate substrates, where they can eventually become predominant due to their low light requirement and ability to penetrate deeper into the carbonate matrix of the skeleton (Chazottes et al. 1995, Le Campion-Alsumard et al. 1995, Tribollet et al. 2006).

Although endolithic algae have been known for more than 100 yr (Duerden 1902, Odum \& Odum 1955), their ecological significance and ecophysiology is still underexplored, especially with respect to their microenvironment and in situ activity. A prominent feature of their natural habitat is the extreme low light levels present within the coral skeleton. It was estimated that 95 to $99 \%$ of the incident photosynthetically available radiation (PAR) is already absorbed by the symbiotic zooxanthellae in the coral tissue (Halldal 1968, Schlichter et al. 1997) and light is then further attenuated by the inorganic skeleton before reaching the actual zone of algal growth (Kanwisher \& Wainwright 1967, Shibata \& Haxo 1969). Estimates of the actual levels of photosynthetically active radiation reaching the green band of endoliths within living corals range from $<0.01$ to $2 \%$ of the incident irradiance at the coral surface (Kanwisher \& Wainwright 1967, Shibata \& Haxo 1969, Halldal 1968, Schlichter et al. 1997).

Only a few measurements of light penetration in coral skeleton have been published and the large variation in irradiance levels estimated to reach the endolithic algae can in part be explained by the use of different methodology and corals with different skeleton structure. Irradiance levels within coral skeletons have either been estimated from light transmission measurements on coral tissue only (Schlichter et al. 1997) or on skeleton slabs held in front of a light meter (Shibata \& Haxo 1969). Alternatively, direct light measurements have been done by inserting relatively large ( $\mathrm{mm}$ to $\mathrm{cm}$ sized) light sensors into predrilled holes within the skeleton (Kanwisher \& Wainwright 1967, Fine et al. 2005). Except for Fine et al. (2005), who used a calibrated quantum irradiance meter, the other published studies did not quantify light intensity in terms of irradiance or scalar irradiance because of non-ideal light-collecting properties of their instrumentation. Earlier light measurements in coral skeleton mostly focused on PAR, while the fate of nearinfrared radiation (NIR) has not been investigated in detail. NIR can drive anoxygenic photosynthesis in bacteria harbouring bacteriochlorophylls (reviewed in Overmann \& Garcia-Pichel 2000).

In some corals, the strong attenuation of light can be alleviated by light-guiding phenomena in the corallites (Highsmith 1981), and multiple scattering in the skeleton matrix may also be of importance for the internal light field in coral skeleton (Kühl et al. 1995, Enriquez et al. 2005). Strong light-scattering creates a diffuse light field within the coral skeleton, where total light availability for photosynthesis can best be quantified as scalar irradiance, i.e. the integral radiant flux incident from all directions about a fixed point (Kühl \& Jørgensen 1994).

The goal of this study was to quantify the spectral scalar irradiance (400 to $950 \mathrm{~nm}$ ) available to endolithic phototrophs within living corals more precisely than reported in the existing literature. We used field radiance and scalar irradiance microprobes (reviewed in Kühl 2005) to (1) measure spectral reflectance characteristics of the endolithic community, and (2) quantify the spectral scalar irradiance within the skeleton of the scleractinian corals Porites cylindrica and different colour morphs of Montipora monasteriata.

\section{MATERIALS AND METHODS}

Study site. Experiments were carried out in January to March 2005 at the University of Queensland research station on Heron Island, located in the Capricorn Bunker group of islands in the southern section of the Australian Great Barrier Reef $\left(23^{\circ} 27^{\prime} \mathrm{S}, 151^{\circ} 54^{\prime} \mathrm{E}\right)$. Corals for the study were collected from the surrounding Heron reef. Porites cylindrica were collected from the reef flat at depths around $1 \mathrm{~m}$, while colour morphs of Montipora monasteriata were collected from the reef crest at 3 to $5 \mathrm{~m}$ depths. Only corals containing green endolithic bands were used for further analysis. The collected corals were cut with a diamond saw while flushing the specimen with seawater. M. monasteriata was cut into square fragments of about $3 \times 5 \mathrm{~cm}$ and P. cylindrica into 3 to $5 \mathrm{~cm}$ long branches (Fig. 1). Sections of individual coral pieces were photographed and the thickness of the green algal band and their depths within the coral skeleton were measured. Prior to the measurements, the coral pieces were kept in shaded outdoor aquaria with flow-through seawater. Care was taken to minimise the light exposure of the cut surface with endoliths during sample handling and incubation. 

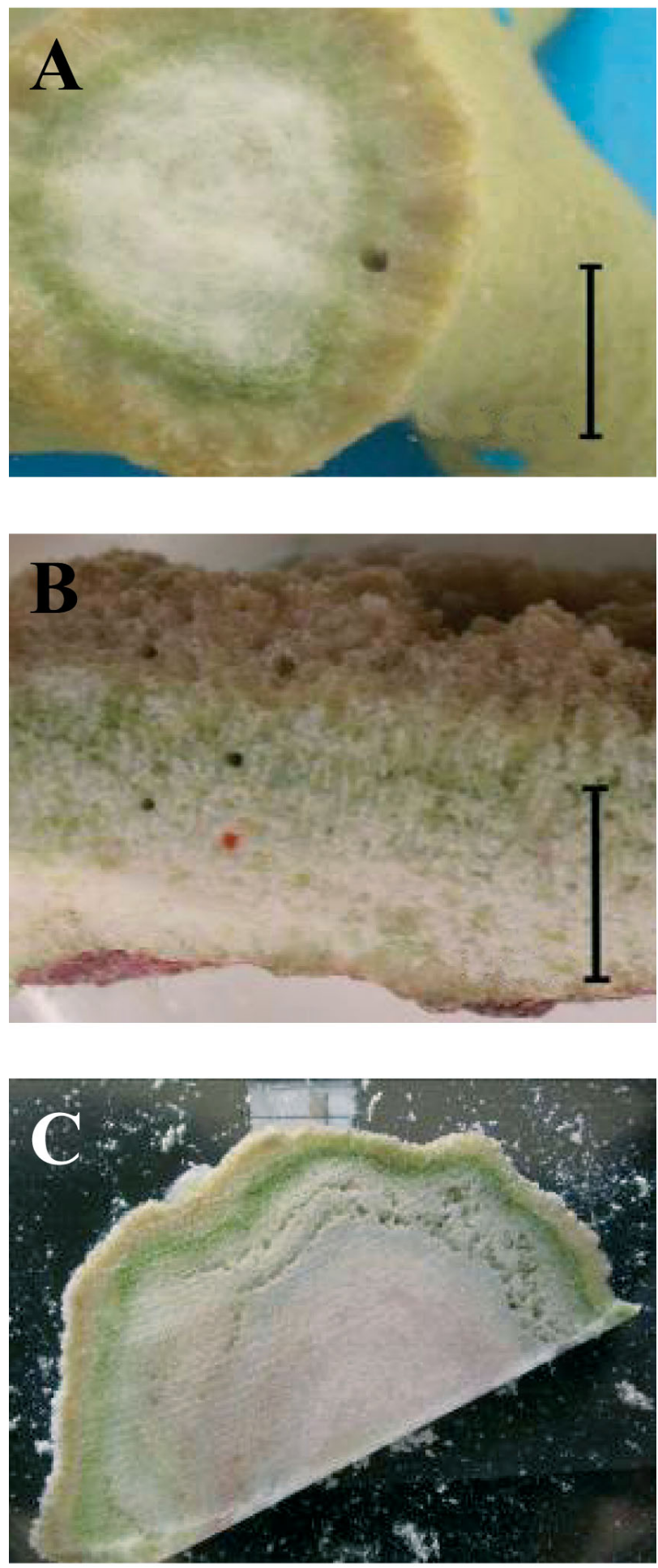

Fig. 1. (A) Porites cylindrica, (B) Montipora monasteriata, (C) Porites sp. Sections of corals showing band of endolithic algae Ostreobium spp. growing within the coral skeleton of $P$. cylindrica and $M$. monasteriata brown morph, and endolithic banding in vertical cut through Porites sp. colony. Note small holes drilled into the skeleton, into which microsensors were inserted. Scale bars: (A) $0.5 \mathrm{~cm},(B) 1 \mathrm{~cm}$
Spectral light and reflectance measurements. Microscale measurements of the spectral light conditions within the coral skeleton were done with fibre-optic scalar irradiance microprobes connected to an optical multichannel analyser (PMA-11, Hamamatsu Photonics). The probes consist of a chromium and black enamel-coated, tapered, optical fibre with a 50 to $100 \mu \mathrm{m}$ wide, diffusing sphere of $\mathrm{TiO}_{2}$-doped methacrylate cast onto the fibre tip (Lassen et al. 1992, Kühl et al. 1997). The microprobe was inserted to a depth of 4 to $4.5 \mathrm{~mm}$ into the coral skeleton through a preformed hole drilled directly into the algal band with a $0.5 \mathrm{~mm}$ diameter carbide drill. The coral piece was immersed in seawater with the coral surface facing a horizontally directed light beam. The coral sample was shielded from stray light and measurements were done in a darkened room. The microprobe was positioned inside the hole at a $90^{\circ}$ angle to the light beam using a manually controlled micromanipulator (Märtzhäuser).

Radiance reflectance spectra were measured with a $140 \mu \mathrm{m}$ diameter, untapered fibre-optic, field radiance microprobe made from a flat, cut, optical fibre (Kühl 2005). The field radiance is the radiant flux per unit area and solid angle from a particular direction given by the zenith and azimuth angle in a spherical coordinate system (Kühl \& Jørgensen 1994). The coral was placed in seawater with the cut surface facing the light source, which was incident, from above, at a slight angle. The field radiance probe was positioned 100 to $200 \mu \mathrm{m}$ above the exposed endolith band. Sample illumination was provided by a fibre-optic tungsten-halogen light source equipped with a collimating lens (Schott KL-2500). All measurements were conducted in a darkened room.

All spectra were corrected for the spectral composition and intensity of the light source as follows: The scalar irradiance measurements were normalised to the downwelling incident irradiance measured over a dark well, with the microprobe tip at approximately the same position and distance in the collimated light field as the coral surface. The reflected radiance was normalised to the reflected radiance from a white reflection standard (WS-4, Ocean Optics). Conversion of the light measurements into absolute radiometric units was not possible as the light meter was not radiometrically calibrated.

In the following, we section the spectral light field into (1) photosynthetically available radiation (PAR, 400 to $700 \mathrm{~nm}$ ) for oxygenic phototrophs with chlorophyll a (chl a) as the primary photopigment, and (2) near-infrared radiation (NIR, >700 nm), which can be used by anoxygenic phototrophic bacteria with bacteriochlorophylls. Some oxygenic phototrophs, including Ostreobium spp., can harvest a minor part of the NIR (so-called far-red light at 700 to $730 \mathrm{~nm}$ ) through special chlorophyll antenna (see also Kühl et al. 2007). 


\section{RESULTS}

\section{Algal band measurements}

In both Porites cylindrica and Montipora monasteriata (brown morph) a distinct zone of dense green algal growth was observed underneath the coral surface, in most cases separated from the coral tissue by a lighter green or whitish zone (Fig. 1). In some specimens, the algal band was growing directly beneath the coral tissue without any discernible intermediate zone. The algal zone was on average thicker and grew deeper within the coral skeleton of $M$. monasteriata, which had more heterogeneous corallites than P. cylindrica. The distance of the green endolith band from the coral surface was on average $4.4 \mathrm{~mm}$ for $M$. monasteriata and $2.3 \mathrm{~mm}$ for $P$. cylindrica, and the average width of the algal band was 1.9 and $0.9 \mathrm{~mm}$ for the 2 corals, respectively (Table 1 ).

\section{Scalar irradiance spectra}

Photosynthetically available radiation (PAR, 400 to $700 \mathrm{~nm}$ ) was strongly attenuated in the coral tissue and skeleton matrix (Fig. 2). More than 90 to $99 \%$ of the incident irradiance in the visible spectrum was absorbed in the upper tissue-containing layers of the coral, with lowest attenuation in Porites cylindrica. At the level of the green endolithic band PAR was attenuated to $<0.1$ to $2 \%$ of the incident irradiance, while the scalar irradiance below the endolithic band was 1 order of magnitude lower. A more extensive data-set with higher replication of spectral scalar irradiance measurements in the green endolithic band (Fig. 3) showed that $<0.1$ to $1.5 \%$ and $<1$ to $15 \%$ of the incident irradiance of PAR at the coral surface reached the dense growth zone of endolithic algae in Montipora monasteriata and P. cylindrica, respectively.

Blue-green light (450 to $550 \mathrm{~nm}$ ) and red light (around the chl a absorption maximum of $675 \mathrm{~nm}$ ) was attenuated most strongly. Minor shoulders in the scalar irradiance transmission spectra indicated spec-

Table 1. Porites cylindrica and Montipora monasteriata. Mean \pm SD distance from Ostreobium sp. band to skeletal surface and width of algal band. Range of measurements is given in parentheses; $\mathrm{n}=$ number of specimens measured

\begin{tabular}{|lccc|}
\hline Species & Distance $(\mathrm{mm})$ & Bandwidth $(\mathrm{mm})$ & $\mathrm{n}$ \\
\hline P. cylindrica & $2.3 \pm 0.3(1.9-2.8)$ & $0.9 \pm 0.3(0.6-1.5)$ & 13 \\
M. monasteriata & $4.4 \pm 1.0(3.0-6.6)$ & $1.9 \pm 0.8(1.0-4.2)$ & 20 \\
\hline
\end{tabular}

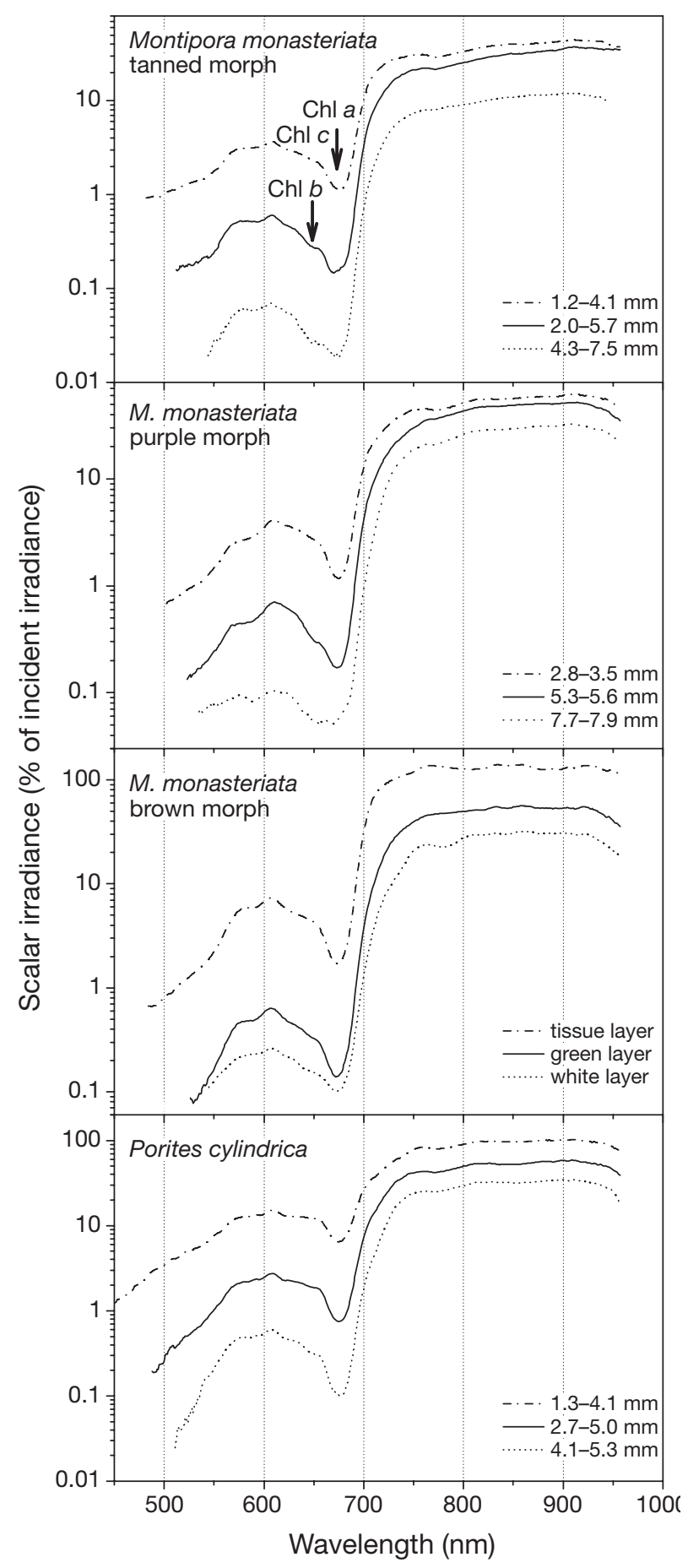

Fig. 2. Porites cylindrica and Montipora monasteriata. Spectral scalar irradiance (\% of incident downwelling irradiance) measured at different depths within skeletons. Top curves in each panel were measured in skeleton directly under coral tissue, central curves within green band of endolithic algae, and bottom curves in skeleton below the green band. Data normalised to incident downwelling irradiance at coral surface. Curves were averaged from multiple measurements $(\mathrm{n}=$ $M$. monasteriata tanned morph, 4; purple morph, 4; brown morph, 4; P. cylindrica, 5). Values in keys $(\mathrm{mm})$ indicate depth range of measurements relative to coral surface 


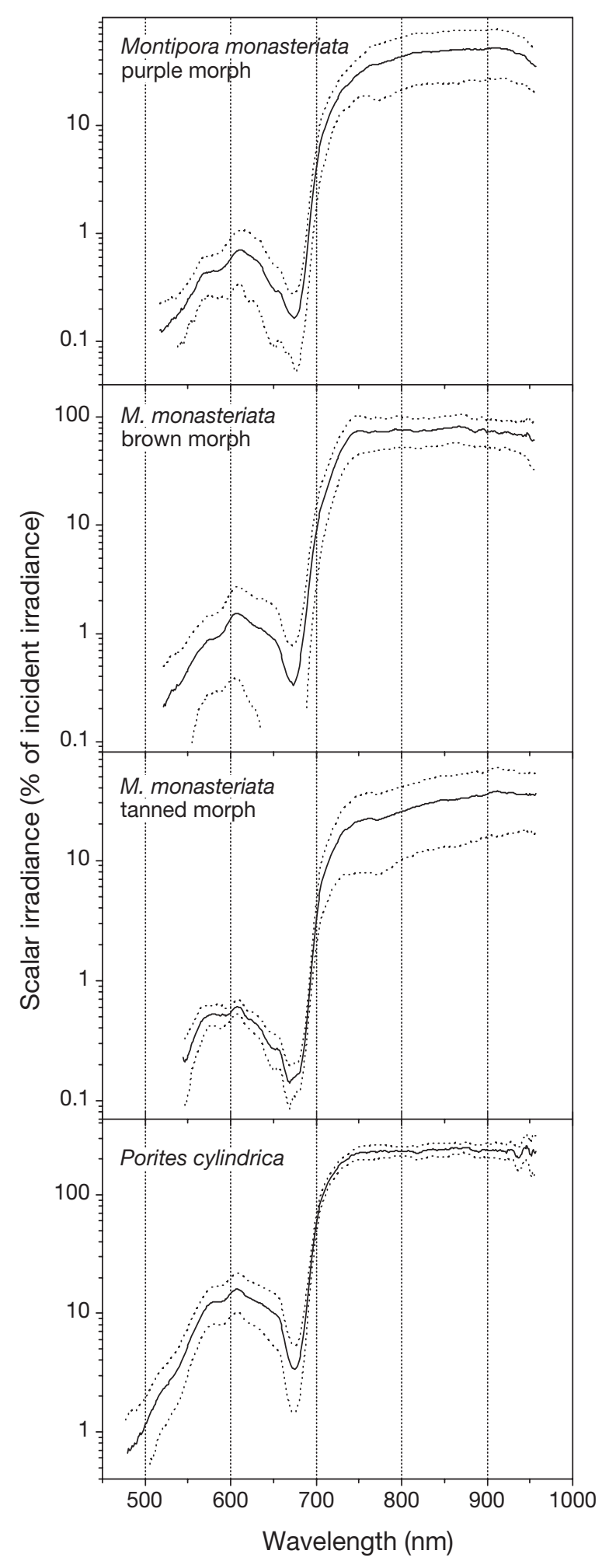

Fig. 3. Porites cylindrica and Montipora monasteriata. Spectral scalar irradiance in green endolithic band within skeletons. Data normalised to incident downwelling irradiance at coral surface (continuous curve $=$ mean, dotted curves $=$ standard deviations; $\mathrm{n}=M$. monasteriata purple morph, 4 ; brown morph, 15 ; tanned morph, $4 ;$ P. cylindrica, 10) tral signatures (arrowed in Fig. 2) of zooxanthellae (chl $c, \sim 635 \mathrm{~nm}$ ), green algae (chl $b, \sim 650 \mathrm{~nm}$ ), and signatures of cyanobacterial phycobiliproteins (580 to $620 \mathrm{~nm})$.

Near-infrared light (NIR, 700 to $950 \mathrm{~nm}$ ) was attenuated much less in the coral, and NIR scalar irradiance reached 10- to almost 1000-fold higher levels than PAR at similar depths within the coral. In the upper skeleton layers, NIR scalar irradiance remained close to or even surpassed $100 \%$ of the incident irradiance (Fig. 3). Within the green endolith layer, NIR scalar irradiance was 20 to $80 \%$ of the incident irradiance for the Montipora monasteriata morphs $(20,70$ and $80 \%$ for the brown, purple and tanned morphs, respectively), while NIR scalar irradiance in the green layer of Porites cylindrica reached $\sim 200 \%$ of the incident irradiance. Even below the green endolith band, NIR levels up to $10-30 \%$ of the incident irradiance were observed. Spectral signatures in the NIR were generally less conspicuous than in the reflectance spectra (see next subsection) but indicated the presence of bacteriochlorophylls in all layers.

\section{Reflectance spectra}

The radiance reflectance spectra measured from skeletal layers with coral tissue and endoliths, respectively, revealed more detailed and clearer spectral signatures of the photopigments present (Fig. 4). High levels of chl a resulted in distinct reflectance minima at $\sim 40$ and 670 to $680 \mathrm{~nm}$, both in layers with coral tissue and endoliths. Absorption by dinoflagellate chl $C$ at $\sim 635 \mathrm{~nm}$ was most pronounced in layers with coral tissue, especially in Porites cylindrica. The green endolithic layers exhibited the presence of chl $b$ originating in Osreobium sp., causing increased absorption around 470 and $650 \mathrm{~nm}$.

We found some spectral signatures of cyanobacterial phycobilins at 580 to $620 \mathrm{~nm}$, and anoxygenic photosynthetic bacteria containing bacteriochlorophyll (Bchl) $C$ ( 750 nm) and Bchl a ( 800 and 860 to $880 \mathrm{~nm})$ in both layers with coral tissue and endoliths within Montipora monasteriata. Measurements in Porites cylindrica also revealed the presence of phycobilins and bacteriochlorophylls in both layers. The absorption characteristics of bacteriochlorophylls in P. cylindrica were, however, different from those observed in $M$. monasteriata and showed reflectance minima at $\sim 760$ to $780 \mathrm{~nm}$ and 840 to $850 \mathrm{~nm}$.

In the endolith layer of Montipora monasteriata and in both coral tissue and endolith layers in Porites cylindrica, a shoulder in reflectance spectra at 700 to $730 \mathrm{~nm}$ indicated an enhanced absorption in the farred region. 


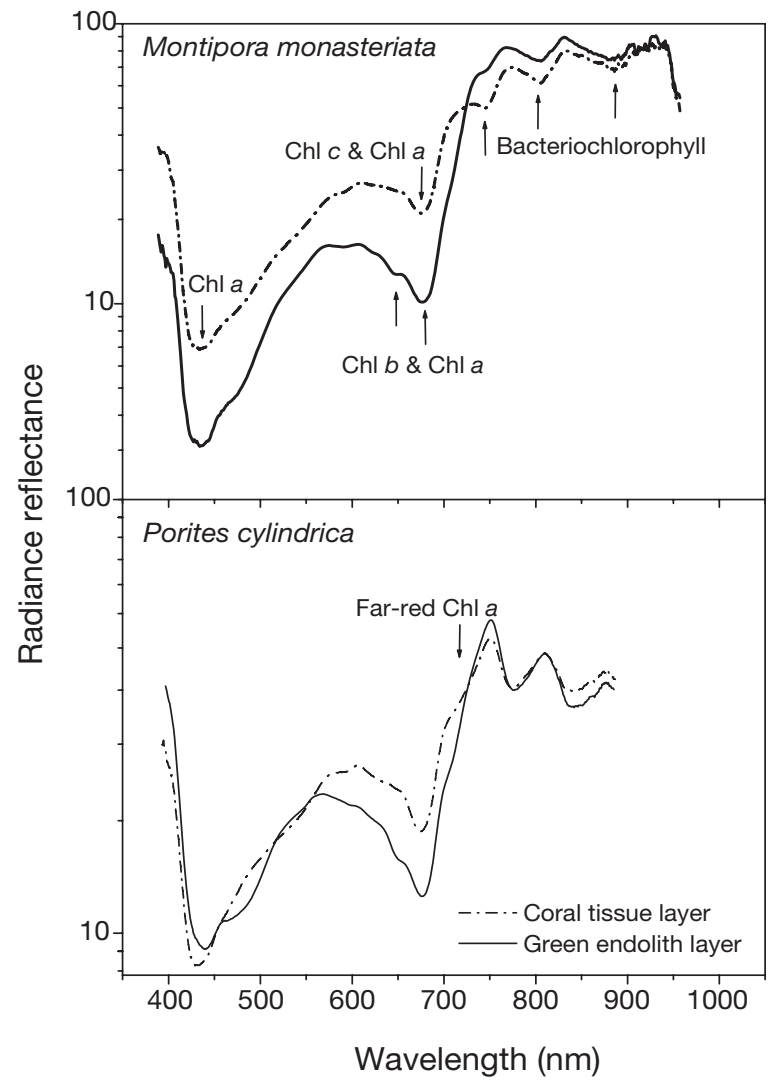

Fig. 4. Porites cylindrica and Montipora monasteriata. Average radiance reflectance spectra (\% of reflection standard) from coral tissue-containing skeleton layer (dotted curve) and from green endolith layer (continuous curve) within corals. Data normalised to reflected radiance from a white reflection standard. ( $\mathrm{n}=$ M. monasteriata 3 ; P. cylindrica, 5 ; SDs not shown)

\section{DISCUSSION}

This study presents new and the so far most detailed measurements of the intensity and spectral composition of light available to endolithic algae within the skeleton of living corals. We used fibre-optic microsensors to measure scalar irradiance levels and spectral quality of the light field within the coral skeleton. Our measurements show that endolithic oxygenic phototrophs like Ostreobium sp. and cyanobacteria exist under extreme low levels of PAR inside corals, while NIR penetrates efficiently into the coral skeleton and can possibly support anoxygenic phototrophic bacteria containing various bacterichlorophylls as well as oxygenic phototrophs absorbing in the far-red with the help of specialised chlorophyll antenna pigments.

\section{Spectral light penetration - PAR}

Our scalar irradiance measurements showed a strong attenuation of visible light in the coral tissue and only a minor fraction of the incident PAR penetrated through the skeleton and reached the endolithic algal band. Earlier estimates (Halldal 1968, Shibata \& Haxo 1969) of $<0.01$ to $2 \%$ of incident PAR available for photosynthesis at the depth of the green endolith band are quite consistent with our measurements, which showed attenuation of $\sim 90$ to $99 \%$ of the incident PAR in the upper tissue-containing layer of the coral. However, the scalar irradiance levels varied greatly between the 2 species studied. About 10 times more light was observed within the green endolith layer of Porites cylindrica compared to that of Montipora monasteriata.

Apart from water depth, there are 2 main factors that most strongly influence the PAR levels within the coral skeleton: (1) attenuation in the tissue due to zooxanthellae absorption and, (2) multiple scattering and light transmission by the skeleton (Shibata \& Haxo 1969, Enriquez et al. 2005). A portion of the light penetrating the tissue is scattered from the skeleton back into the tissue, resulting in increased absorption capability by the endosymbiotic algae and modification of the light climate within the tissue and skeleton. The chlorophyll content of the zooxanthellae and host pigments (Salih et al. 2000) can also influence PAR absorption. Our measurements were conducted on healthy corals without any signs of bleaching, and pigmentation did not show large variation between specimens of the same species and between colour morphs.

The difference in PAR levels at the depth of the endolith band between the 2 species studied is most likely due to the combination of the greater tissue thickness of Montipora monasteriata (data not shown), and the fact that the green endolithic band resides significantly deeper within $M$. monasteriata than within Porites cylindrica (Table 1). Light must therefore travel a considerably greater distance through both tissue and skeleton before reaching the algal band in M. monasteriata. When the light levels at corresponding depths within the 2 coral species are compared, a greater similarity in irradiance levels of PAR is observed (Fig. 2). However, differences in skeletal microstructure and light-guidance along corallites may also affect the transmission of light through the skeleton (Highsmith 1981) and this aspect of light propagation in corals should be investigated in more detail.

\section{Spectral light penetration - NIR}

The light field within the corals was highly enriched in NIR wavelengths. While earlier estimates of the transmission and irradiance levels of PAR in the coral are largely in agreement with our data, earlier estimates on the levels of longer wavelengths penetrating 
the tissue were far too low. In our study, the irradiance levels of 700 and $720 \mathrm{~nm}$ light, i.e. far-red light, measured directly within the green algal band were 3 to $5 \%$ and 12 to $34 \%$ of surface downwelling irradiance, respectively, for Montipora monasteriata morphs, and 56 and $145 \%$, respectively, for Porites cylindrica. These are much higher values than the 1 to $2 \%$ of incident far-red irradiance previously estimated to be transmitted through the dinoflagellate layer (Shibata \& Haxo 1969). The reasons for this large discrepancy lie largely in the fact that earlier studies did not take the light-scattering properties of the skeleton into account. NIR is not subject to absorption by the zooxanthellae and apparently passes readily through the coral tissue. Hence NIR levels in the coral are principally determined by scattering within the coral structure rather than by absorption in the tissue; scattering of NIR within the skeleton is also evident from the higher than incident irradiance levels in the uppermost parts of the skeleton (Figs. 2 \& 3).

Estimates of light levels within the skeleton have thus far been based on downwelling irradiance or undefined measures of light intensity as the measuring parameter. However, multiple light scattering in the coral skeleton creates a diffuse light field (Enriquez et al. 2005), in which the endolithic algae receive light from all directions. Scalar irradiance is therefore the most relevant measure of available light within the coral skeleton, and downwelling irradiance measurements underestimate the light actually available, especially at wavelengths subject to intense scattering and low absorption (Kirk 1994, Kühl \& Jørgensen 1994, Kühl et al. 1994).

Intense scattering in the skeleton can cause photontrapping phenomena similar to those known from optical studies of sediments, plant and animal tissue exhibiting multiple scattering (see Kühl \& Jørgensen 1994 and references therein). Briefly, intense scattering of incident light causes a significant increase in photon pathlength per vertical distance traversed in the skeleton. This increases the local residence time of such scattered photons, adding a significant portion of diffuse light to the incident photon flux. In addition, some lightguiding in the skeleton matrix (Highsmith 1981) may also contribute to the NIR maximum seen in the upper skeleton layers. These effects are most pronounced at wavelengths where there is low or no absorption - in our case mainly in the NIR part of the spectrum. For PAR, the mentioned light-trapping effects leading to an increased photon pathlength actually increase the probability of absorption due to the much higher amounts of pigments absorbing visible light in the coral skeleton (see also Enriquez et al. 2005).

We have shown that NIR penetrates efficiently into corals, but the absolute amount of NIR available for photosynthesis will be strongly affected by the inherent absorption of NIR in the overlaying water. In pure seawater, the irradiance attenuation coefficient for $700 \mathrm{~nm}$ light, $K_{d}(700 \mathrm{~nm})$ is about $0.62 \mathrm{~m}^{-1}$ and attenuation increases with increasing wavelength; $K_{d}(800 \mathrm{~nm})$ is about $2.07 \mathrm{~m}^{-1}$ (Smith \& Baker 1981). Using these values and assuming exponential attenuation with depth, it can be calculated that for $700 \mathrm{~nm}$ light, $10 \%$ of incident irradiance remains at $\sim 3.7 \mathrm{~m}$, and $1 \%$ remains at $\sim 7.4 \mathrm{~m}$ depths. For $800 \mathrm{~nm}$ light 10 and $1 \%$ of the incident irradiance remain at $\sim 1.1$ and $\sim 2.2 \mathrm{~m}$, respectively. In comparison, $K_{d}(440 \mathrm{~nm})$ is $\sim 0.009 \mathrm{~m}^{-1}$, and blue light reaches the 10 and $1 \%$ level at 255 and $512 \mathrm{~m}$ depths, respectively, in pure seawater. NIR-driven photosynthesis can thus only be expected in shallow-water corals, but it remains to be investigated at which depth NIR depletion in the overlaying water becomes limiting for the distribution and activity of phototrophs.

Obviously, while far-red wavelengths may be sufficiently abundant in shallow reef waters, it is paradoxical how and why bacteriochlorophyll-containing microbes thrive in the coral skeleton when NIR at $800 \mathrm{~nm}$ and beyond is attenuated so strongly in water. This calls for more detailed in situ light measurements as well as photophysiological measurements on endoliths using defined NIR levels in the laboratory.

\section{Photopigment diversity}

The reflectance spectra showed the presence of a diverse community of endolithic phototrophs living within the coral skeleton. The green band was dominated by Ostreobium sp., which can contain high levels of chl $b$ (about $2 / 3$ the content of chl $a$, Jeffrey 1968). We also found some evidence for far-red absorbing photopigments seen as a shoulder of lower reflectance around 700 to $720 \mathrm{~nm}$ in the green endolith band. Far-red absorbing chl a antenna pigments have been reported in Ostreobium sp. from photosynthetic action spectra (Halldal 1968) as well as from fluorescence and absorption spectra from both cultures and coral sections (Fork \& Larkum 1989, Koehne et al. 1999). It was speculated that such spectral adaptation allows Ostreobium sp. to persist under extreme shade (Halldal 1968, Le Campion-Alsumard 1995, Koehne et al. 1999). Recently, Wilhelm \& Jakob (2006) demonstrated that Ostreobium sp. can indeed grow quite efficiently under monochromatic far-red illumination at $\sim 700 \mathrm{~nm}$.

Besides Ostreobium sp., we also detected distinct spectral signatures of bacterial phototrophs in the skeleton, i.e. both cyanobacterial phycobilins and bacteriochlorophylls indicative of the presence of 
anoxygenic phototrophic bacteria. Cyanobacteria have previously been found within corals (Lesser et al. 2004), albeit their presence has mainly been reported in microscopic studies of dead coral skeletons (Lukas 1974, Le Campion-Alsumard et al. 1995). Recent spectral reflectance measurements along with pigment analysis on 5 different corals, showed the presence of cyanobacteria as well as anoxygenic photosynthetic bacteria growing as bands occurring below the green Ostreobium sp.-dominated layer within deeper layers of the skeleton (Ralph et al. in press). Extraction and quantification of the water-soluble phycobiliproteins was attempted, but proved difficult due to strong adherence of the pigments to the coral carbonate skeleton.

We found the bacteriochlorophyll signatures to be present throughout the skeletal compartment, both below and above the concentrated green Ostreobium sp. band. This widespread occurrence of bacteriochlorophylls may indicate that anoxygenic phototrophs are an important and hitherto ignored component of shallow-water corals, although such bacteria have been detected in several molecular surveys of bacterial diversity in corals (e.g. Bourne \& Munn 2005). Coral tissue and skeleton exhibit nitrogen fixation activity (e.g. Crossland \& Barnes 1976, Williams et al. 1987, Shashar et al. 1994). Interestingly, many anoxygenic phototrophic bacteria can fix nitrogen, and we speculate that such bacteria may contribute to the nitrogen budget of corals and endoliths in addition to the recently discovered symbiotic cyanobacteria in corals (Lesser et al. 2004). Our data show the presence of bacteriochlorophyll in the skeleton both in coral tissue-containing layers and in deeper layers, but we have no evidence at all so far that NIR actually supports anoxygenic phototrophs in the coral skeleton, and further investigation of the metabolic activity of endolithic anoxygenic phototrophs in coral skeleton is necessary.

\section{Endolith photophysiology}

The unique set of photopigments in Ostreobium sp., i.e. special chlorophyll antenna absorbing in the 700 to $725 \mathrm{~nm}$ part of the spectrum, along with its high $\mathrm{chl} b$ concentration and ability to dynamically up- and down-regulate their light-harvesting complexes, makes the photosynthetic performance of this alga very flexible, permitting its survival under diverse light conditions and allowing its competitive success under extreme shade (Halldal 1968, Fork \& Larkum 1989, Koehne et al. 1999).

Our data show that the interior of shallow-water corals presents a niche enriched in NIR light. Under such conditions, Ostreobium sp. are able to up-regulate their light-harvesting complex, containing the farred absorbing chlorophyll forms, as well as increase their chl $b$ concentration (Halldal 1968, Koehne et al. 1999), allowing enhanced capture of available wavelengths and increased photosynthetic efficiency. The algae are able to be photosynthetically active at very low light intensities (Halldal 1968, Shashar \& Stambler 1992) and are capable of surviving prolonged exposure to $<0.1-0.01 \mu \mathrm{mol}$ photons $\mathrm{m}^{-2} \mathrm{~s}^{-1}$ (Schlichter et al. 1997). However, under such extreme shade-adaptation, measurements of oxygen production indicate low photosynthetic activity by the endoliths (Kanwisher \& Wainwright 1967, Shashar \& Stambler 1992, Schlichter et al. 1997, S. H. Magnusson et al. unpubl. data).

Wilhelm \& Jakob (2006) investigated the growth and quantum yield of Oestreobium sp. and O. queketti under far-red light and showed that quanta absorbed in the long wavelength antenna can drive oxygenic photosynthesis via an uphill-energy transfer. Growth was quite effective under $\sim 700 \mathrm{~nm}$, but the maximum quantum yield of PSII activity was lowered significantly. The chl $d$-containing cyanobacterium Acaryochloris marina is another oxygenic phototroph that can persist in NIR-enriched habitats below dense layers of other phototrophs (Kühl et al. 2005, 2007) but we have so far not found any indication for chl $d$ in corals.

The strong light limitation of endolith photosynthesis in the coral can be alleviated by removal of the coral tissue (e.g. through predation or disease) or by loss of coral symbionts through bleaching, leading to increased light penetration into the coral skeleton. When introduced to increased levels of PAR, Ostreobium spp. are able to photoacclimate and adapt their photosynthetic performance to increased irradiance by optimising their pigmentation (Fork \& Larkum 1989), leading to a blooming of endolith biomass closer to the coral surface (Fine et al. 2002, 2004). $O$. quekettii in skeletal fragments showed no significant photoinhibition at PAR levels up to $250 \mu \mathrm{mol}$ photons $\mathrm{m}^{-2} \mathrm{~s}^{-1}$ (Schlichter et al. 1997), although such high irradiance levels are well above the natural range experienced within the skeleton of healthy corals. It has been speculated that the increased transport of endolithic photoassimilates during periods of bleaching may enhance the recovery of the coral colony (Fine \& Loya 2002). Endolithic phototrophs may thus be an important and hitherto underexplored component of coral ecology. Further microsensor studies on the effects of increased light and temperature on the endolithic activity and microenvironment during coral bleaching are now underway and will give further important insights into the photophysiology of these endolithic communities. 
Acknowledgements. This study was supported by the Australian Research Council (M.F. and M.K.), and the Danish Natural Science Research Council (M.K.). Additional support of S.H.M. arose through funding by the University of Copenhagen and the Centre for Marine Studies, University of Queensland. A. Glud is thanked for microsensor fabrication. The Heron Island Research Station staff provided excellent facilities and technical support. We thank 4 anonymous reviewers for their help in improving the original submitted manuscript.

\section{LITERATURE CITED}

Bellwood DR (1995) Carbonate transport and within-reef patterns of bioerosion and sediment release by parrotfish (family Scaridae) on the Great Barrier Reef. Mar Ecol Prog Ser 117:127-136

Bourne DG, Munn CB (2005) diversity of bacteria associated with the coral Pocillopora damicornis from the Great Barrier Reef. Environ Microbiol 7:1162-1174

Chazottes V, Le Campion-Alsumard T, Peyrot-Clausade M (1995) Bioerosion rates on coral reefs: interaction between macroborers, microborers and grazers (Moorea, French Polynesia). Palaeogeogr Palaeoclimatol Palaeogeol 113: 189-198

Crossland CJ, Barnes DJ (1976) Acetylene reduction by coral skeletons. Limnol Oceanogr 21:153-156

Duerden JE (1902) Boring algae as agents in the disintegration of corals. Bull Am Mus Nat Hist 16:323-332

Enriquez S, Méndez ER, Iglesias-Prieto R (2005) Multiple scattering on coral skeletons enhances light absorption by symbiotic algae. Limnol Oceanogr 50:1025-1031

Ferrer LM, Szmant AM (1989) Nutrient regeneration by the endolithic community in corals. Proc 6th Int Coral Reef Symp 3:1-4

Fine M, Loya Y (2002) Endolithic algae: an alternative source of photoassimilates during coral bleaching. Proc R Soc Lond Ser B 269:1205-1210

Fine M, Steindler L, Loya Y (2004) Endolithic algae photoacclimate to increased irradiance during coral bleaching. Mar Freshw Res 55:115-121

Fine M, Metroz-Fine E, Hoegh-Guldberg O (2005) Tolerance of endolithic algae to elevated temperature and light in the coral Montipora monasteriata from the southern Great Barrier Reef. J Exp Biol 280:75-81

Fork DC, Larkum AWD (1989) Light harvesting in the green algae Ostreobium sp., a coral symbiont adapted to extreme shade. Mar Biol 103:381-385

Halldal P (1968) Photosynthetic capacities and photosynthetic action spectra of endozoic algae of the massive coral Favia. Biol Bull (Woods Hole) 134:411-424

Highsmith RC (1981) Lime boring algae in hermatypic corals skeletons. J Exp Mar Biol 55:267-281

Jeffrey SW (1968) Pigment composition of Siphonales algae in the brain coral Favia. Biol Bull (Woods Hole) 135: 141-148

Kanwisher JW, Wainwright SA (1967) Oxygen balance in some reef corals. Biol Bull (Woods Hole) 133:378-390

Kirk JTO (1994) Light and photosynthesis in aquatic ecosystems. Cambridge University Press, Cambridge

Koehne B, Elli G, Jennings RC, Wilhelm C, Trissl HW (1999) Spectroscopic and molecular characterization of a long wavelength absorbing antenna of Ostreobium sp. Biochim Biophys Acta 1412:94-107

Kühl M (2005) Optical microsensors for analysis of microbial communities. Methods Enzymol 397:166-199
Kühl M, Jørgensen BB (1994) The light field of microbenthic communities: radiance distribution and microscale optics of sandy costal sediments. Limnol Oceanogr 39:1368-1398

Kühl M, Lassen C, Jørgensen BB (1994) Light penetration and light intensity in sandy marine sediments measured with irradiance and scalar irradiance fibre-optic microprobes. Mar Ecol Prog Ser 105:139-148

Kühl M, Cohen Y, Dalsgaard T, Jørgensen BB, Revsbech NP (1995) The microenvironment and photosynthesis of zooxanthellae in scleractinian corals studied with microsensors for $\mathrm{O}_{2}, \mathrm{pH}$ and light. Mar Ecol Prog Ser 117:159-172

Kühl M, Lassen C, Revsbech NP (1997) A simple light meter for measurements of PAR (400-700 nm) with fibre-optic microprobes: application for P vs. I measurements in microbenthic communities. Aquat Microb Ecol 13:197-207

Kühl M, Chen M, Ralph PJ, Schreiber U, Larkum AWD (2005) A niche for cyanobacteria containing chlorophyll $d$. Nature 433:820

Kühl M, Chen M, Larkum AWD (2007) Biology of the chlorophyll $d$-containing cyanobacterium Acaryochloris marina. In: Seckbach J (ed) Extremophilic algae, cyanobacteria and non-photosynthetic protists: from prokaryotes to astrobiology. Springer-Verlag, Berlin (in press)

Lassen C, Ploug H, Jørgensen BB (1992) A fibre-optic scalar irradiance microsensor; application for spectral light measurements in sediments. Microb Ecol 86:247-254

Le Campion-Alsumard T, Goubic S, Hutchings P (1995) Microbial endoliths in skeletons of live and dead corals: Porites lobata (Moorea, French Polynesia). Mar Ecol Prog Ser 117:149-157

Lesser MP, Mazel CH, Gorbunov MY, Falkowski PG (2004) Discovery of symbiotic nitrogen-fixing cyanobacteria in corals. Science 305:997-1000

Lukas KJ (1973) Taxonomy and ecology of the endolithic microflora of reef corals with review of the literature on endolithic microphytes. PhD thesis, University of Rhode Island, Kingston

Lukas KJ (1974) Two species of the chlorophyte genus Oestreobium from skeletons of Atlantic and Caribbean reef corals. J Phycol 10:331-335

Odum HT, Odum EP (1955) Trophic structure and productivity of a windward coral reef community on Eniwetok Atoll. Ecol Monogr 25:291-320

Overmann J, Garcia-Pichel F (2000) The phototrophic way of life. The prokaryotes. Springer-Verlag, New York (also available at: http://ep.springer-ny.com:6336/contents/)

Ralph PJ, Larkum AWD, Kühl M (in press) Photobiology of endolithic microorganisms in living coral skeletons: pigmentation, spectral reflectance and variable chlorophyll fluorescence analysis of endoliths in the massive corals Cyphastrea serailia, Porites lutea and Goniastrea australensis. Mar Biol

Salih A, Larkum AWD, Cox G, Kühl M, Hoegh-Guldberg O (2000) Fluorescent pigments in corals are photoprotective. Nature 408:850-853

Schlichter D, Conrady S, Kampmann H, Klüter A, Krisch H, Kuhrau LM, Zscharnack B (1996) Carbonate production of scleractinians in dependence upon the availability of food and the trophic potential of endolithic algae. In: Reitner J, Neuweiler F, Gunkel F (eds) Global and regional controls on biogenic sedimentation. I. Reef evolution. Research reports. Göttingen, Göttinger Arb Geol Paläont Sb2, p 111-118

Schlichter D, Kampmann H, Conrady S (1997) Trophic potential and photoecology of endolithic algae living within coral skeletons. PSZN I: Mar Ecol 18:299-317 
Shashar N, Stambler N (1992) Endolithic algae within corals - life in an extreme environment. J Exp Mar Biol 163:167-173

Shashar N, Cohen Y, Loya Y, Sar N (1994) Nitrogen fixation (acetylene reduction) in stony corals: evidence for coral-bacteria interactions. Mar Ecol Prog Ser 111:259-264

Shibata K, Haxo FT (1969) Light transmission and spectral distribution through epi- and endozoic algal layers in the brain coral, Favia. Biol Bull (Woods Hole) 136:461-468

Smith RC, Baker KS (1981) Optical properties of the clearest natural waters (200-800 nm). Appl Optics 20:177-184

Editorial responsibility: Howard Browman (Associate Editorin-Chief), Storebø, Norway
Tribollet A, Langdon C, Golubic S, Atkinson M (2006) Endolithic microflora are major primary producers in dead carbonate substrates of Hawaiian coral reefs. J Phycol 42: 292-303

Wilhelm C, Jakob T (2006) Uphill energy transfer from longwavelength absorbing chlorophylls to PSII in Ostreobium sp. is functional in carbon assimilation. Photosynth Res 87: 323-329

Williams WM, Viner AB, Broughton WJ (1987) Nitrogen fixation (acetylene reduction) associated with the living coral Acropora variabilis. Mar Biol 94:531-535

Submitted: February 16, 2006; Accepted: August 17, 2006 Proofs received from author(s): February 21, 2007 